\title{
MANAGEMENT OF MONKEY PROBLEM IN ALIGARH MUSLIM UNIVERSITY CAMPUS, UTTAR PRADESH
}

\author{
Ekwal Imam and H.S.A. Yahya \\ Department of Wildlife Sciences, Aligarh Muslim University, Aligarh, India
}

\begin{abstract}
Several Rhesus Monkey bites reported from the ALigarh Muslim University Campus prompted the University Health department and the Provost of S.N. Hall to curb the monkey menace. The monkey trapping/shifting was undertaken during January-February 2000 and January 2001. Out of 27 Rhesus monkeys, 22 were trapped and shifted to the semi-natural forest area of Jawan, Aligarh District. This paper reports the attempt to shift the monkeys but does not substantiate the validity of the exercise for want of post transfer monitoring.
\end{abstract}

\section{Keywords}

Macaca mulatta, Rhesus monkey, Aligarh University, menace, rehabilitation

\section{Introduction}

India is endowed with one-tenth of the world's primate species. All primate species found in the country are commonly known as bandar (Macaca mulatta) and have great cultural and religious value. Orthodox Hindus consider monkeys as sacred animals, to be revered and protected. This reverence stems partly from the role of the monkey god, Hanuman, in the Ramayana.

There are over 0.3 million Rhesus Monkeys in northern India (Malik, 1992). Approximately $48.5 \%$ of these are living in human habitation areas (Southwick \& Siddiqi, 1994). This inordinate increase in population of such monkeys in recent years has led to an unhealthy competition for space and food between man and monkey. Attracted by food, water and shelter the monkey troops invade settlements and often destroy human property such as cars, gardens and furnishings inside residences. Moreover, the monkeys of the Aligarh Muslim University Campus (AMU) were creating other social problems, such as stealing of clothes and eatable items, uprooting of vegetables and garden plants, etc. These type of activities were more prevalent in Girls hostel, University Polytechnic and Sulaiman Hall. Irate humans often resort to abusing monkeys. In retaliation, the monkeys have become over aggressive, resulting in an increased incidence of monkey bites.

Of all the non-destructive control measures, "shifting of problem creating animals" was found to be the best method (Southwick et al., 1984; Forthman-Quick, 1986; Else, 1991). Before the monkey problem scaled off in Aligarh, Siddiqi and Southwick (1993), Southwick and Siddiqi (1994, 1998), Imam, (1991a,b, 2000) and Imam and Yahya, (1995) had earlier suggested to shift some of the Rhesus Monkeys from the district.

On account of their oppressive behaviour, some commensal monkeys from other parts of the country have been shifted earlier. In february 1995, five groups of Rhesus Monkeys comprising of 40 individuals were moved from National Zoological Park, New Delhi and released in Tughlaqabad Fort, New Delhi (Imam \& Malik, 1997) and in the same year seven individuals trapped from Friendicos, New Delhi were released in Tughlaqabad Fort, New Delhi. In one of the world's largest monkey capture and release exercises, 600 monkeys from Vrindaban (Mathura District) were captured and released in different forest patches (Imam et al., in press). Encouraged by the above-mentioned programmes, it was decided to adopt the same technique to solve the Campus monkey problem.

\section{Methods}

During implementation of the project, monkeys were baited, trapped, transported and released at the new site. Trapping was continued for 10 days in the first phase and seven days in the second phase. Monkeys were trapped with the help of a portable trapping cage made of iron $(2 \times 2 \times 2 \mathrm{~m})$ having a heavy sliding door. The sliding door was tied to a pulley. The pulley tied with thin iron wire was operated by a man from a distance of $20 \mathrm{~m}$, hidden in a drum or hideout with a view-slit. Banana (Musa paradisiaca) and dry-roasted Bengal Gram (Cicer aerietinum) were selected as baits as these were one of the favoured food items of monkeys. Before starting the trapping, baits were spread 
inside the cage and the sliding-door was kept open. The bananas helped in attracting the monkeys towards the cage. As monkeys entered the trapping cage, they started picking Bengal gram. Because of the small size of the gram the monkeys had to spend more time inside the trapping cage. This provided enough opportunity to shut the door by releasing the pulley. Thereafter, trapped monkeys were transferred carefully into the holding cage of $0.5 \times 0.5 \times 0.5 \mathrm{~m}$, then finally into the releasing cage of $5 \times$ $2.5 \times 2.5 \mathrm{~m}$ size. Releasing cages, with trapped monkeys, were loaded on to the Jeep for transportation. The cage had provision for food and water for trapped animals. The monkeys were transported to the pre-selected suitable site and released near trees. To avoid onlookers, release operation was done during evening.

Trapping began in the morning and continued till sunset. From different localities of the University Campus 11 adult males, seven adult females, three juveniles and one infant were trapped. It was decided not to release these monkeys in those areas, which already have resident monkey groups. Therefore, the trapped monkeys were shifted to forest patches of Jawan canal.

\section{Results and Discussion}

Shrinkage of natural forest due to expansion in horticulture, urbanization and industrilization have forced Rhesus Monkeys to shift from their natural habitats to cities, towns, villages and to agricultural areas. Furthermore, the ban on the export of primates from India in 1978 has also helped in increasing their population. Total protection in the absence of any natural predator and peoples' religious and traditional attachments have also contributed in their population growth (Southwick \& Siddiqi, 1988). Since there is hardly any forest area near Aligarh, the unchecked increase in their population might lead to overcrowding. Southwick (1967) and Alexander (1974) observed

Table 1. Translocation of monkeys from AMU campus to seminatural forest of Jawan (Aligarh)

\begin{tabular}{llllll}
\hline Date & Trapping locality & \multicolumn{4}{c}{ No. trapped and translocated } \\
\cline { 3 - 6 } & & Male & Female & Juvenile & Infant \\
\hline 25.1 .2000 & University polytechnic & 01 & - & - & - \\
25.1 .2000 & Abrar girls' hostel & 02 & 01 & & 01 \\
26.1 .2000 & Abrar girls' hostel & 04 & 01 & 03 & - \\
27.1 .2000 & Abrar girls' hostel & 01 & - & - & - \\
29.1 .200 & Abrar girls' hostel & 01 & 03 & & \\
12.1 .2001 & S.N. girls' hostel & 01 & 02 & - & - \\
17.1 .2001 & S.N. girls' hostel & 01 & - & - & - \\
& Total & 11 & 07 & 03 & 01 \\
\hline
\end{tabular}

that aggression in captive groups of Rhesus and Japanese monkey increased under crowding. Such intraspecific aggression may deprive food for sick monkeys. In addition, their frequent contact with humans may enhance the chances of transmission of potential diseases (e.g. Shigella, Salmonella, Microbacterium) from monkey to human and vice versa (Shah $\&$ Southwick, 1965; Tiwari \& Shukla, 1984). Though no disease outbreak within any human community in India has ever been unequivocably linked to monkey-human contact so far, the potential for such mishaps exist.

With the increase in the population of monkey nuisance in suburban and urban areas, their activities are becoming intolerable and they are viewed more as vermin than as species of conservation importance. This is not only true for Aligarh (AMU campus), but for all monkey-infested areas of the country. Detailed post-release studies at the present release sites and elsewhere are required.

\section{Acknowledgements}

We acknowledge the University authority (AMU, Aligarh) for financial support. We are also thankful to staff of Department of Wildlife Sciences and students of Abrar Hostel and S.N. Hall for their co-operation extended during trapping operation.

\section{References}

Alexander, R.D. (1974). Evolution of social behaviour. Annual Review of Ecological System 5: 324-382.

Else, J.G. (1991). Non human primates as pests, pp. 156-165. In: Box, H.O., Editor, Primate Response to Environmental Change. Chapman \& Hall, London.

Forthman-Quick, D.L. (1986). Controlling Primate Pests: The Feasibility of Conditioned Taste Aversion, pp. 252-273. In: Taub, D.M. and F.A. King, Editors, Current Perspectives in Primate Social Dynamics. Van Nostrand Rheinhold, New York.

Imam, E. (1991a). Translocation: A proposal for the conservation and management of Rhesus Monkey in Aligarh District. Zoos' Print, 8(4): 3-4.

Imam, E. (1991b). Population distribution of Rhesus Monkey Macaca mulatta in and around Aligarh. M.Phil. Dissertation, Aligarh Muslim University, Aligarh (UP), India.

Imam, E. (2000). A study on some behavioural aspects of Rhesus monkey Macaca mulatta in Aligarh and adjoining districts. Ph.D. Thesis, Aligarh Muslim University, Aligarh (UP), India.

Imam, E. and H.S.A. Yahya (1995). Population dynamics and distribution of Rhesus Monkey in Aligarh District. Journal of Ecobiology 8(3) 1-9.

Imam, E. and I. Malik (1997). Translocation of monkeys from National Zoological Park, New Delhi to Tughlaqabad Fort, South Delhi: A report. Vatavaran and National Zoological Park, New Delhi.

Imam, E., H.S.A. Yahya and I. Malik (in press). A successful mass translocation of commensal Rhesus Monkeys Macaca mulatta in Vrindaban, India. Oryx

Malik, I. (1992). Introduction. In: Schwibbe, M.H. and I. Malik, Editors, Primatology in India: Primate Report 34: 3-4. 
Shah, K.V. and C.H. Southwick (1965). Prevalence of antibodies to certain viruses in sera of free-living and captive Rhesus Monkey. Indian Journal of Medical Research 53: 488-500.

Siddiqi, M.F. and C.H. Southwick (1993). Translocation of Rhesus Macaques in India. In: Mast, R. and A.H. Mitchell, Editors, Conservation and Management of Primates. Sunny Press, Binghamton. Southwick, C.H. (1967). An experimental study of intra-group agonistic behaviour in Rhesus Monkey. Behaviour (Leiden) 28: 182209.

Southwick, C.H., M.F. Siddiqi and R. Johnson (1984). Subgroup relocation of Rhesus Monkeys in India as conservation measure. American Journal of Primatology 6: 428.

Southwick, C.H. and M.F. Siddiqi (1988). Partial recovery and new population estimation of Rhesus Monkey population in India. American Journal of Primatology 16: 187-197.

Southwick, C.H. and M.F. Siddiqi (1994). Primate commensalism: the Rhesus Monkey in India. Review of Ecology (Terre vie) 49: 223231.

Southwick, C.H. and M.F. Siddiqi (1998). The Rhesus Monkey's fall from grace, pp. 211-218. In: Ciochon, R.L. and R.A. Nisbett, Editors, The Primate Anthology: Essays on Primate Behaviour, Ecology, and Conservation. Prentice Hall, New Jersey.

Tiwari, J.P. and L.K. Shukla (1984). Microbiological investigation of Rhesus Macaque, Macaca mulatta, in an urban setting in Uttar Pradesh, India, pp. 497-499. In: Roonwall, M.L., S.M. Mohnot and N.S. Rathore, Editors, Current Primate Research. University of Jodhpur, India.

\section{ON SOME MISCONCEPTIONS ON CONSERVATION OF INSECTS}

\section{T.C. Narendran ${ }^{1}$ and P.T. Cherian ${ }^{2}$}

${ }^{1}$ Professor, Systematic Entomology Laboratory, Department of Zoology, University of Calicut, Kerala 673635, India.

${ }^{2}$ Additional Director, Zoological Survey of India, 100 Santhome High Road, Chennai, Tamil Nadu 600028, India.

Insects are by far the oldest, most numerous and smallest flying machines. Comprising 9.5 lakh described species, they account for about $73 \%$ of the animal species of the world reported so far. On the basis of information available on groups on which taxonomic studies have reasonably advanced, India, covering 2.2 per cent of the global land surface, harbours seven to eight per cent of the world's fauna (Cherian, 1996). If so, it is reasonable to presume that India may be home to approximately 0.67 lakh insect species, of which hardly $10 \%$ have so far been named (Purvis \& Hector, 2000). Of those already discovered, over $99 \%$ are known only by a scientific name, a handful of specimens in museums and a few scraps of anatomical descriptions in scientific journals (Wilson, 1992). The knowledge of taxonomy of immature stages of insects is far behind that of adults. Today, only in a few groups can it contribute meaningfully to the classification of the group.

Need for systematic studies on insect fauna: There is a great dearth of experts on the vast majority of insect groups globally, and all the more so in India. A typical case is the shortage of experts on termites, the owners of $10 \%$ of the animal biomass in the tropics.

There are exactly three people qualified to deal with termite classification on a world-wide basis (Wilson, 1992) and none of that caliber in India. It is the same case with most of the speciose groups of insects. The need to know more about our insect faunal wealth is really great.

Conservation of insects vis-a-vis vertebrates: Because of their small size and modest needs, most insects and other invertebrates occupy ecological niches that are more numerous and smaller in all dimensions (space, time and so on) and therefore more sensitive than those of vertebrates. Furthermore, the needs of invertebrates do not always coincide with those of vertebrates. Besides, individuals in populations of insects of most of the species far outnumber those of vertebrates. Often they can

Received 9 March 2001

Accepted 10 October 2001 